\title{
Residual currents in the Severn Estuary and their effects on dispersion
}

Residual currents Numerical mode Bristol Channel Severn Estuary Estuarine dispersion

Courants résiduels Modèle numérique Canal de Bristol

Estuaire de la Severn Dispersion estuarienne

\section{R.J. Uncles}

Natural Environment Research Council, Institute for Marine Environmental Research, Prospect Place, The Hoe, Plymouth PL1 3DH, UK.

Received $8 / 1 / 82$, in revised form $7 / 4 / 82$, accepted $15 / 4 / 82$.

\section{ABSTRACT}

Depth averaged residual currents and associated water levels resulting from $\mathrm{M}_{2}$ tidal oscillations in a numerical model of the Severn Estuary, UK, are presented. Current patterns are dominated by eddies.

Residual currents produce enhanced transverse and axial dispersion by the mechanism of tidal "random walk". The axial dispersion coefficient due to residual current eddies is shown to be comparable to the observed long-term value for the seaward section of estuary considered, and is much greater than values which can be attributed to vertical shear in tidal and residual currents, or transverse shear in tidal currents. Transverse mixing due to tidal "random walk" is found to be much greater than that which can be attributed to other known mechanisms. Estuarine width is shown to be important in that it limits the size of horizontal eddies, and therefore controls the dispersion for given tidal and residual current speeds.

Oceanol. Acta, 1982, 5, 4, 403-410.

\section{Les courants résiduels de l'estuaire de la Severn et leurs effets sur la dis- persion}

Les courants résiduels dont la moyenne est prise verticalement et les niveaux d'eau associés résultant des oscillations d'une marée $\mathrm{M}_{2}$ dans un modèle numérique de l'estuaire du Severn (UK), sont présentés. Les courants sont dominés par des tourbillons.

Les courants résiduels créent une dispersion transversale et axiale, augmentée par le mécanisme du " random walk " des marées. On constate que le coefficient de dispersion axiale est comparable à la valeur à long terme observée pour la section marine de l'estuaire, et qu'il est beaucoup plus élevé que les valeurs associées au cisaillement vertical des courants de marées et résiduels ou au cisaillement transversal des courants des marées. Le mélange transversal créé par le « random walk " des marées est supérieur à celui attribuable aux autres mécanismes connus. La largeur de l'estuaire a de l'importance parce qu'elle limite la grandeur des tourbillons et, par conséquent, règle la dispersion pour des vitesses données de courants de marées et résiduels.

Oceanol. Acta., 1982, 5, 4, 403-410.

\section{INTRODUCTION}

The purpose of this paper is to present data on tidallyinduced residual current patterns in a seaward section of the Severn, a wide, vertically mixed estuary, and to demonstrate their importance to both the axial and transverse dispersion properties of the region. Residual currents are computed using a depth-averaged, twodimensional, hydrodynamical model of the $\mathrm{M}_{2}$ tide. Contours showing the computed semimajor axis of the $\mathrm{M}_{2}$ tidal current ellipse are drawn in Figure 1. The dispersion mechanism considered here arises through the 


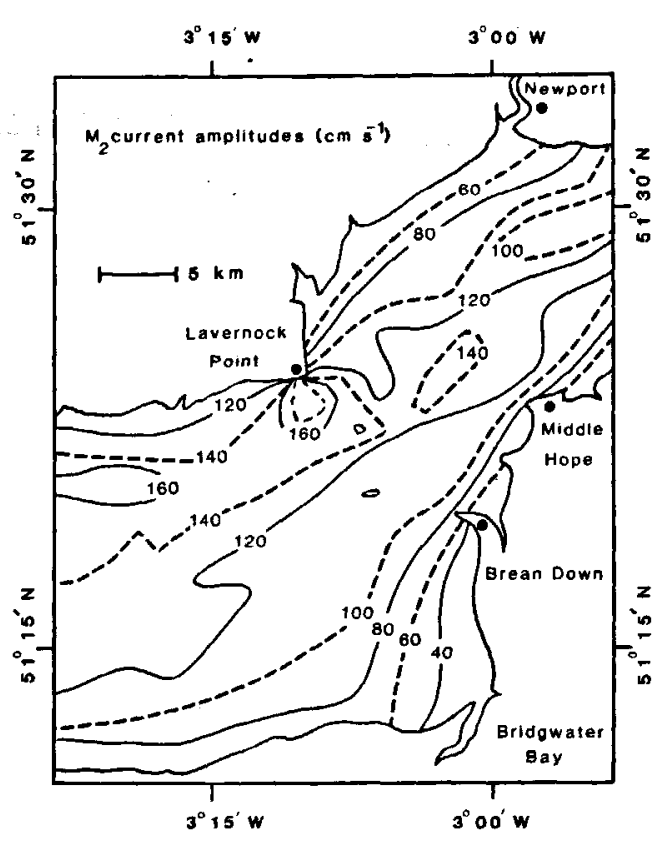

Figure 1

Computed semimajor axis of $M_{2}$ tidal ellipses ( $\left.\mathrm{cm} \mathrm{sec}{ }^{-1}\right)$.

process of tidal "random walk", which has been investigated by Zimmerman (1976) for the Wadden Sea, and which depends on the length-scales and speed-scales associated with the distribution of residual current eddies in the sea area.

The efficacy with which tidal non-linearities are able to generate residual currents in shallow regions has been demonstrated theoretically many times (see for example, Nihoul, Ronday, 1975; Tee, 1976; Pingree, 1978; Prandle, 1978; Zimmerman, 1978 a); some laboratory and field studies which support the general theoretical findings are listed by Zimmerman (1978 $a$ ). Individual contributions to the residual current have recently been investigated for the Bristol Channel and western Severn Estuary in order to understand how each mechanism for non-linear generation produces a current, and to compare these currents with those driven by horizontal density gradients (Uncles, 1982). In general, depthaveraged residual currents due to advection of tidal momentum are largest, followed by those due to nonlinearities in the continuity equation. Depth-averaged residual flows due to horizontal density gradients appear to be comparatively small in the western Severn Estuary (Uncles, 1982), and are ignored in this paper, although the effect of such density gradients on the vertical structure of residual currents can be significant (Uncles, Jordan, 1979; Uncles, 1982).

The mechanism whereby residual currents are generated through advection of tidal momentum is easy to visualise in a region such as the Severn, where ellipticity of the dominant semidiurnal tidal currents is negligible (Uncles, 1981). Essentially, the driving force perpendicular to curving tidal streams is the centrifugal force, which is in the same direction on flood and ebb streams, and is thus able to maintain a residual set-up of water level (Stewart, 1957). Residual currents flow where the surface slopes due to the residual set-up do not exactly balance centrifugal forces. The driving force parallel to the tidal streams is related to the parallel gradient of tidally-averaged kinetic energy. Zimmerman $(1978 b)$ has shown how these advection processes can give rise to residual current eddies when a tidal flow interacts with complicated bottom topography. A particularly graphical illustration of how advection nonlinearities can influence dispersion in a tidal channel is given by Murty et al. (1980).

\section{EQUATIONS AND METHODS}

\section{Numerical model}

The depth-averaged equations of continuity and momentum are solved in their standard non-linear forms (equations (1) and (2) of Uncles, 1982). Meteorological and density gradient effects are ignored. The Coriolis parameter is $1.14 \times 10^{-4} \mathrm{sec}^{-1}$, acceleration due to gravity, $g$, is $980 \mathrm{~cm} \mathrm{sec} .^{-2}$, the friction parameter in the quadratic drag law is $2.5 \times 10^{-3}$, and the coefficient of horizontal eddy viscosity, $\mathrm{N}$, is $10^{6} \mathrm{~cm}^{2}$ sec. ${ }^{-1}$. This value of $\mathrm{N}$ has been used in a number of modelling studies (eg: Tee, 1976; Pingree, Maddock, 1977), although computed patterns of tidal and residual currents are insensitive to its value (Tee, 1976).

The equations are solved in finite-difference form using a $(49 \times 68)$ array of points with a spacing of $(1.0 \times 1.0 \mathrm{~km})$ to cover the Severn Estuary between $\left(2^{\circ} 35^{\prime} \mathrm{W}-3^{\circ} 35^{\prime} \mathrm{W}, 51^{\circ} 11^{\prime} \mathrm{N}-51^{\circ} 38^{\prime} \mathrm{N}\right)$. The numerical methods employed are essentially the same as those described by Flather and Heaps (1975). Seaward boundary conditions on the elevations consist of data for the residual, and for the $\mathrm{M}_{2}$ and $\mathrm{M}_{4}$ tides. These data were obtained by interpolating results from a larger, coarsegrid model of the Bristol Channel (Uncles, 1982), having a lattice spacing of $(3.1 \times 3.1 \mathrm{~km})$.

The model uses the actual coastline shape and bottom depths everywhere except on tidal flats. Depths over these regions are modelled as being $5 \mathrm{~m}$ relative to mean sea level, which means that they have depths of less than $1 \mathrm{~m}$ at low water. This procedure avoids the generation of spurious residual flows which can occur during the simulated covering and uncovering of tidal flats, whilst only slightly decreasing the realism of the model. Solutions obtained for the region shown in Figure 1, but with tidal flats incorporated, are very similar to those computed here except that they do not satisfy conservation of water volume exactly.

The modelled region is larger than that for which results are presented (see Fig. 1). The seaward boundary of the model lies roughly $15 \mathrm{~km}$ west of the region drawn in Figure 1, and its landward boundary extends some $25 \mathrm{~km}$ further up-estuary; this avoids the presentation of possible spurious circulations at both the open boundary (Prandle, 1978, p. 198), and in the poorly represented area of extensive tidal flats in the upper Severn. 
Residual elevations and currents are derived from the numerical solutions by averaging computed values over an $\mathrm{M}_{2}$ tidal cycle. Residual currents and elevations are denoted by $\mathbf{u}$ and $\zeta$. The semimajor axis of the $\mathbf{M}_{2}$ tidal current (Fig. 1) is denoted by $\mathrm{U}_{0}$.

\section{RESULTS}

\section{Residual currents}

Figure 2 shows the depth-averaged Eulerian residual currents, u, computed using the model and displayed over a limited seaward stretch of the estuary. These currents are not constrained to satisfy conservation of tidally-averaged water volume because they include a net down-estuary component which attempts to compensate for the up-estuary directed Stokes drift (a nonlinear continuity effect, Tee, 1976; Uncles, Jordan, 1980; Uncles, 1982). That the currents shown in Figure 2 are not predominantly down-estuary confirms that the major generating mechanism in the region is non-linear advection (Uncles, 1982); this was also shown by Tee (1976) to be the case for the Minas Basin, Bay of Fundy.

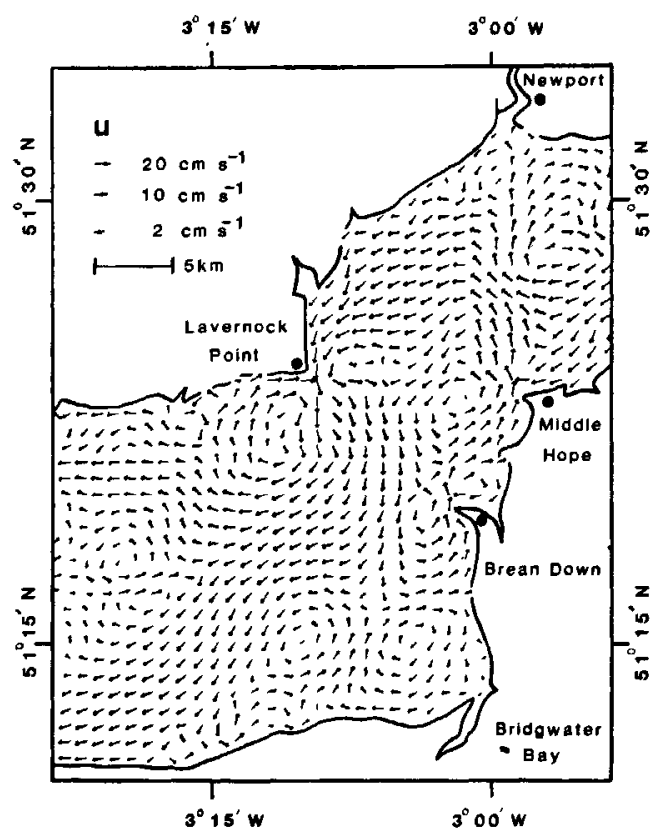

Figure 2

Computed depth-averaged Eulerian residual currents for $M_{2}$ tides, u. Speeds are drawn using a logarithmic scale.

The current pattern in Figure 2 is very similar to that computed by Owen (1980) using a model of the eastern Bristol Channel with a $(1.37 \times 1.29 \mathrm{~km})$ grid spacing, and by Uncles (1982), and shows a number of residual current eddies which can be attributed to interaction of the tidal flow with complex bottom and coastline topography through non-linear advection of momentum (Zimmerman, $1978 a_{2} b$; Pingree, 1978). The Eulerian residual transport velocity, $\mathbf{u}_{T}$ (defined here to be the

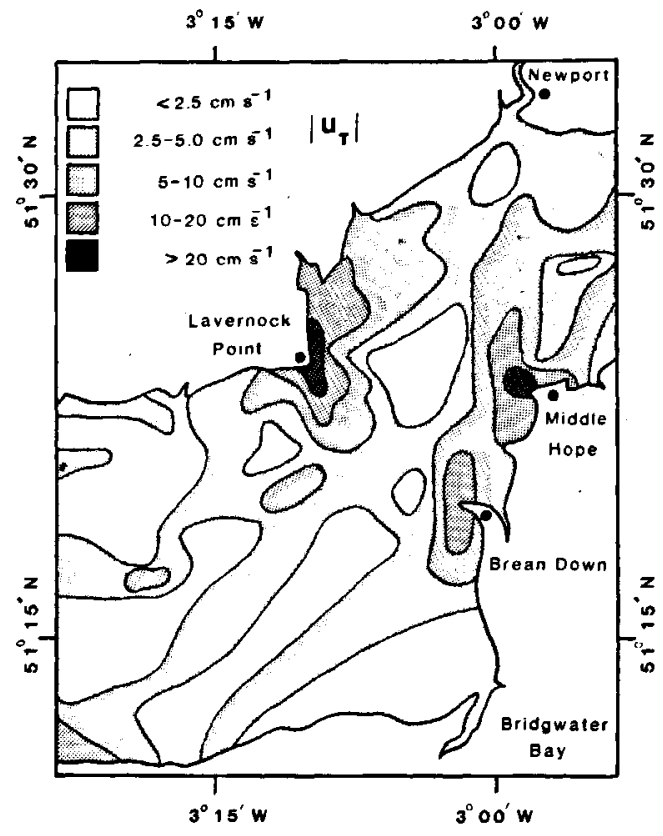

Figure 3

Computed depth-averaged Eulerian transport residual current speeds for $\mathbf{M}_{2}$ tides, $\mathbf{u}_{T}$.

residual rate of transport of water volume per unit width of water column, divided by the tidally-averaged depth) has also been computed. Conservation of tidally-averaged water volume requires that the current patterns for $\mathbf{u}_{T}$ ultimately form closed loops in the estuary under steady conditions with no freshwater inputs. However, current patterns for $\mathbf{u}_{T}$ are very similar to those for $u$, and are therefore not presented. The magnitude of $\mathbf{u}_{T}$ (and essentially also that of $\mathbf{u}$ ) is shown in Figure 3; a typical current speed is $5 \mathrm{~cm} \mathrm{sec.}^{-1}$, although speeds in excess of $20 \mathrm{~cm} \mathrm{sec}^{-1}$ can occur off the headlands at Lavernock Point and Middle Hope.

Direct reading current meters have been deployed at several stations in the region shown in Figure 2, and depth-averaged residual currents estimated from these data (see Uncles, Jordan, 1979, for results from two of these stations). A comparison of computed with observed currents shows striking similarities, thereby providing some experimental evidence that Figure 2 provides a realistic picture of residual flow in the area.

\section{Water levels}

'The flood tidal currents sweep from East to North-East between Brean Down and Lavernock Point, and from North-East to East between Middle Hope and Newport. In both cases the associated centrifugal forces are directed across the estuary away from the centres of curvature. The residual set-up of water level, $\zeta$, due to $\mathbf{M}_{2}$ tidal non-linearities is shown in Figure 4. The intense depressions of water level at Lavernock Point and Middle Hope, and the fast residual currents which occur there, are localised headland effects (see Pingree, 1978 and the references cited). The more gentle gradients in water level between Lavernock Point and Bridgwater Bay, and between Middle Hope and Newport, which dominate the contour patterns in Figure 4, 


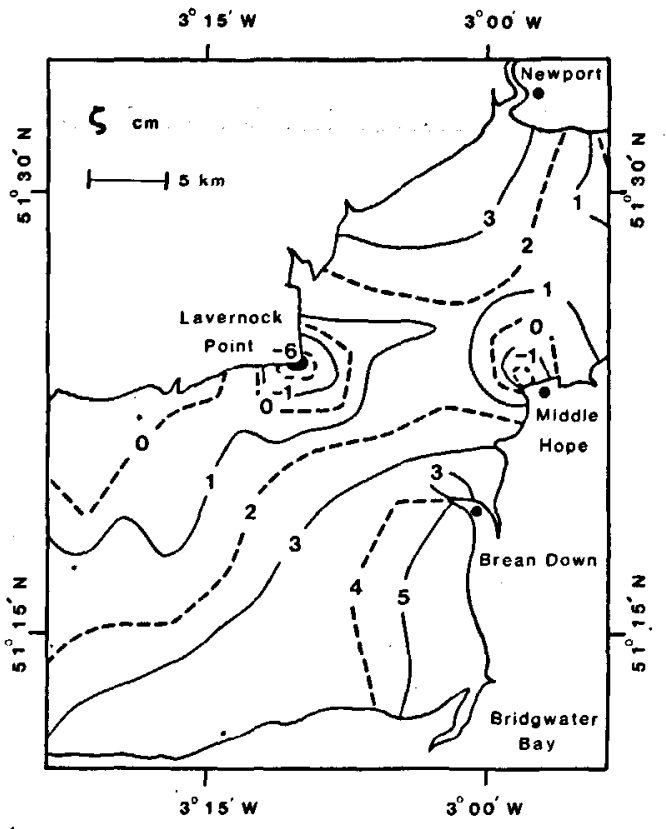

Figure 4

Computed residual water levels for $M_{2}$ tides, $\zeta(\mathrm{cm})$, relative to an arbitrary datum.

can be attributed to estuary-wide centrifugal forcing of the curving tidal streams. Using equation (8) of Uncles (1982) it can be shown for the region between Brean Down and Lavernock Point that :

$\mathrm{U}_{0}^{2} / 2 \mathrm{R}_{0} \cong \mathrm{g} \partial \zeta / \partial r \cong 5 \times 10^{-3} \mathrm{~cm} \mathrm{sec} .^{-2}$

using $\mathrm{U}_{0}=1.2 \mathrm{~m} \mathrm{sec}^{-1}$ (Fig. 1), $\mathrm{R}_{0}=20 \mathrm{~km}$ for the local radius of curvature of the tidal streams, and $r$ as the local cross-estuary co-ordinate. A similar balance exists between Middle Hope and Newport.

\section{DISPERSION}

An important consequence of the complex residual circulation patterns shown in Figure 2 is the increased rate of transverse spreading of water and dissolved materials which they promote. This is easy to visualise in those regions where residual currents tend to flow directly across the estuary; however, Zimmerman $(1976 ; 1978 b)$ has shown theoretically that a random distribution of residual current eddies can also promote transverse (and axial) mixing by introducing a "random walk" component into the motion of a parcel of water as it oscillates up and down estuary in the tidal streams.

The relevance of this extra transverse mixing can be appreciated by considering time-scales for crosssectional mixing based on other mechanisms, of which probably the most important (excluding unknown wind effects) is vertical shear in the transverse residual currents. If, relative to its depth-mean value, a transverse residual current is assumed to decrease linearly from $u_{1}$ at the surface to $-u_{1}$ at the bed, and if the depth-mean vertical mixing coefficient is denoted by $\mathrm{K}_{33}$, then the transverse dispersion coefficient in a depth $h$ is (Fischer et al., 1979, p. 88) :

$\mathrm{K}_{22}=4 \mathrm{u}_{1}^{2} \mathrm{~h}^{2} / 120 \mathrm{~K}_{33}$.

$\mathrm{K}_{33}$ is poorly defined for oscillatory flows. In the vertically homogeneous water of the Severn Estuary it is reasonable to assume that $K_{33}$ is equal to the vertical eddy viscosity, $\mathrm{N}_{33}$, for which Heaps $(1972$, p. 423) gives $\mathrm{N}_{33}=0.1 \mathrm{~h}=150 \mathrm{~cm}^{2} \mathrm{sec}^{-1}$ in $15 \mathrm{~m}$ of water. Observations of residual currents and salinity at a station between Brean Down and Lavernock Point indicate a depth mean value for $K_{33}$ of $60 \mathrm{~cm}^{2} \mathrm{sec}^{-1}$ (Uncles, Jordan, 1979). Using $K_{33}=60 \mathrm{~cm}^{2} \mathrm{sec}^{-1}$ in order to give maximum weighting to $\mathrm{K}_{22}$ in equation (1), and assuming a strong shear in the transverse residual current, with $u_{1}=10 \mathrm{~cm} \mathrm{sec}^{-1}$, then for $h=15$ $m$ equation (1) gives :

$\mathrm{K}_{22}-10 \mathrm{~m}^{2} \mathrm{sec}^{-1}$.

This is probably an overestimate of the dispersion coefficient.

Tidal currents are directed along the axis of the estuary, so that their vertical shear will contribute to axial dispersion, rather than transverse dispersion. Also, the transverse mixing coefficient due to turbulence is typically of the order of $0.1 \mathrm{~m}^{2} \mathrm{sec}^{-1}$ (Talbot, Talbot, 1974) and is thus negligible. Therefore, with $K_{22}=$ $10 \mathrm{~m}^{2} \mathrm{sec}^{-1}$, the time required for complete crosssectional mixing of a dissolved material released at a coastal site in a seaward section of estuary of width (B) $20 \mathrm{~km}$ is (Fischer et al., 1979. p. 117) :

$T_{c}=0.4 \mathrm{~B}^{2} / \mathrm{K}_{22} \cong 200$ days.

This mixing time is comparable with the flushing time of the whole estuary, which varies between 100-200 days (Uncles, Radford, 1980). For one-dimensional water-quality models of the Severn, and associated axial dispersion coefficients, to be physically meaningful (as they appear to be, Uncles, 1979) it is necessary for appreciable transverse mixing of a material to occur during its passage through the estuary, and thus for $K_{22}$ to be much greater than $10 \mathrm{~m}^{2} \mathrm{sec}^{-1}$. Therefore, it is of interest to investigate whether, to order of magnitude, the "random walk" diffusion process described by Zimmerman $(1976 ; 1978 b)$ is able to produce this additional transverse mixing.

\section{Tidal "random walk"}

The "random walk" analysed by Zimmerman (1976) is such that successive displacements of a water parcel (each separated in time by a time-step of half a tidal period, $T_{0} / 2$ ) constitute a first-order Markov process. Although the analysis is too lengthy to be usefully summarized here, the concept of a tidal "random walk" is, nevertheless, easily visualized. Consider the motion of a water parcel which is labelled at the beginning of the ebb. Subsequently, the parcel will move down-estuary and then return during the flood. In absence of residual 
currents and other perturbing influences, the parcel will return to its original position after one tidal period. If, now, the effects of residual currents are incorporated, then the parcel's position at the end of the ebb will be somewhat different from its position in absence of residual currents. The difference between these two positions defines the residual ebb displacement. Similarly, when the water parcel moves up-estuary from its perturbed position at the end of the ebb, it attains a position at the end of the flood which is somewhat different from that which it would have attained in absence of residual currents. The difference between these two positions is the residual flood displacement. Naturally, the residual current field experienced by the parcel during flood tidal streams will be similar to that experienced during the ebb, because the sea areas covered are similar. This means that one can expect successive residual flood and ebb displacements to be partially correlated.

The theory assumes that non-zero correlations only exist between successive residual flood and ebb or ebb and flood displacements. The correlation time-scale for residual displacements is therefore one tidal period, $T_{0}$. If the residual current field is random in space, then successive displacements of the water parcel at intervals of $T_{0}$ will constitute a random vector time series. If now the motion of a cluster of such labelled water parcels is considered (each having a slightly different starting position) then each parcel will perform a tidal "random walk" during its flood and ebb movement. Because each parcel will experience a slightly different residual current field from its neighbours, the cluster as a whole will tend to disperse due to this mechanism.

In Zimmerman's (1976) theory the Eulerian residual current field is assumed to consist of a homogeneous and normal random distribution in space of characteristic eddies represented by a stream function of Gaussian form. Under these conditions the transverse and axial dispersion coefficients may be written :

$\mathrm{K}_{22}=b_{2}(\nu, \lambda) \mathrm{U}_{0} l_{0}$ and $\mathrm{K}_{11}=b_{1}(\nu, \lambda) \mathrm{U}_{0} l_{0}$,

where $l_{0}=\mathrm{U}_{0} / \omega_{0}$ is the amplitude of the tidal excursion, $\omega_{0}=2 \pi / T_{0}$ is the $M_{2}$ angular frequency $\left(1.41 \times 10^{-4} \mathrm{sec}^{-1}\right)$, and where :

$\nu=\left\langle\mathrm{u}^{2}\right\rangle / \mathrm{U}^{2}{ }_{0}$ and $\lambda=l_{0} / l$.

The additional simplifying assumption of isotropy has been made here so that $\left\langle\mathbf{u}^{2}\right\rangle$ is the ensemble mean of the squared residual current speed in a randomly distributed array of eddies of size $l$; essentially, the eddies are considered to be rotationally symmetric. The modifiers, $b_{1}$ and $b_{2}$ in equation (3), relate dispersion to the residual current eddy field. When the residual currents are very weak, $b_{1}, b_{2}$ and the dispersion are very small, and in the limit $b_{1}, b_{2} \rightarrow 0$ as $\nu \rightarrow 0$. Similarly, when the length-scale of the eddies is very small compared with the tidal excursion, then individual water parcels moving with the tidal streams only experience slight perturbations to their trajectories, and the effective mixing is also small; in the limit, $b_{1}, b_{2} \rightarrow 0$ as $\lambda \rightarrow \infty$.
The assumption of isotropic eddies does not lead to isotropic $\left(b_{1}=b_{2}\right)$ dispersion for rectilinear tidal currents, the axial dispersion along the currents is always greater than the transverse dispersion $\left(b_{1}>b_{2}\right)$.

\section{Extension of theory}

An important assumption of the theory is that partial correlations between residual displacements of a water parcel vanish after two time-steps, $T_{0}$. In the case of the Severn it is found that the correlation time-scales for axial and transverse "random walks" $\left(\tau_{1}\right.$ and $\left.\tau_{2}\right)$ greatly exceed $T_{0}$, so that the theory breaks down. To overcome this difficulty the time-step of the "random walk" is increased to $n \mathrm{~T}_{0} / 2$, where $n$ is a positive integer (Zimmerman, pers. comm.). For descriptive purposes no essential detail is lost if the modifications are described for the case of one-dimensional motion. The residual velocity is denoted by $u$, and the tidal velocity by $\mathrm{U}_{0} \sin \omega_{0} t$. If, at $t=0$, a water parcel is situated at - $l_{0}$ relative to the origin, then its residual displacement over one time-step can be estimated as :

$$
\begin{aligned}
\mathrm{y}^{(n)} & =\int_{0}^{n \mathrm{~T}_{0} / 2} \mathrm{u}\left[\int_{0}^{t} \mathrm{U}_{0} \sin \omega_{0} t^{\prime} \mathrm{d} t^{\prime}-l_{0}\right] \mathrm{d} t \\
& =\int_{0}^{n \mathrm{~T}_{0} / 2} \mathrm{u}\left(-l_{0} \cos \omega_{0} t\right) \mathrm{d} t .
\end{aligned}
$$

Using a Fourier (wave-number space) representation of $u$ gives :

$$
\begin{aligned}
\mathrm{y}^{(n)} & =\int_{0}^{n \mathrm{~T}_{0} / 2} \int \mathrm{w}(\mathrm{k}) \exp \left(\mathrm{ik} l_{0} \cos \omega_{0} t\right) \mathrm{dkd} t \\
& =\frac{n \pi}{\omega_{0}} \int \mathrm{w}(\mathrm{k}) \mathrm{J}_{0}\left(\mathrm{k} l_{0}\right) \mathrm{dk}
\end{aligned}
$$

in which $\mathrm{J}_{0}$ is a zero-order Bessel function of the first kind. The ensemble mean square residual displacement is :

$$
\begin{aligned}
\left.<\mathrm{y}^{2}\right\rangle=\frac{n^{2} \pi^{2}}{\omega_{0}^{2}} \iint<\mathrm{w}(\mathrm{k}) \mathrm{w}\left(\mathrm{k}^{\prime}\right) \\
\mathrm{J}_{0}\left(\mathrm{k} l_{0}\right) \mathrm{J}_{0}\left(\mathrm{k}^{\prime} l_{0}\right)>\mathrm{dkdk}^{\prime} .
\end{aligned}
$$

Similarly, the residual displacement over the following time-step is estimated as (see equation (4)) :

$$
\begin{aligned}
& \mathrm{y}^{(n+1)}=\int_{n \mathrm{~T}_{0} / 2}^{n \mathrm{~T}_{0}} \mathrm{u}\left(\mathrm{y}^{(n)}-l_{0} \cos \omega_{0} t\right) \mathrm{d} t \\
& =\int_{n \mathrm{~T}_{0} / 2}^{n \mathrm{~T}_{0}} \int \mathrm{w}\left(\mathrm{k}^{\prime}\right) \exp \left\{-\mathrm{ik}\left(\mathrm{y}^{(n)}-l_{0} \cos \omega_{0} t\right)\right\} \mathrm{d \textrm {k } ^ { \prime } \mathrm { d } t} \\
& =\frac{n \pi}{\omega_{0}} \int \mathrm{w}\left(\mathrm{k}^{\prime}\right) \mathrm{J}_{0}\left(\mathrm{k}^{\prime} l_{0}\right) \exp \left\{-\mathrm{ik} \mathrm{y}^{\prime}(n)\right\} \mathrm{d} \mathrm{k}^{\prime},
\end{aligned}
$$

so that the ensemble average of the product of successive residual displacements is :

$$
\begin{aligned}
& \left\langle\mathrm{y}^{(n)} \mathrm{y}^{(n+1)}\right\rangle=\frac{n^{2} \pi^{2}}{\omega_{0}^{2}} \iint<\mathrm{w}(\mathrm{k}) \mathrm{w}\left(\mathrm{k}^{\prime}\right) \mathrm{J}_{0}\left(\mathrm{kl}_{0}\right) \mathrm{J}_{0}\left(\mathrm{k}^{\prime} l_{0}\right) \text {. } \\
& . \exp \left\{-i k^{\prime} y^{(n)}\right\}>d k d k^{\prime}
\end{aligned}
$$


The correlation coefficient between successive residual displacements, $c$, is :

$c=\left\langle\mathrm{y}^{(n)} \mathrm{y}^{(n+1)}\right\rangle /\left\langle\mathrm{y}^{2}\right\rangle$

with a corresponding correlation time-scale, $\tau$, where :

$\tau=\frac{n \mathrm{~T}_{0}}{2(1-c)}$.

An effective mean square velocity is defined by :

$\left\langle\mathrm{v}^{2}\right\rangle=\left\langle\mathrm{y}^{2}\right\rangle /\left(n \mathrm{~T}_{0} / 2\right)^{2}$,

from which a dispersion coefficient can be determined in the form :

$\mathrm{K}=\left\langle\mathrm{v}^{2}\right\rangle \tau$.

The major effort lies in the evaluation of the integrals in equations (5) and (6), and these are not altered by putting $n \neq 1$ (Zimmerman, 1976); $n$ is evaluated (using trial and error) by ensuring that the time-step is half the correlation time-scale, as it should be in a random walk process where partial correlations vanish after two steps (Zimmerman, pers. comm.).

In two dimensions, the equations used to derive $b_{1}(\nu$, $\lambda)$ and $b_{2}(\nu, \lambda)$ are straightforward extensions of those given by Zimmerman (1976), [his equations (78), (79) and (84)], and may be written :

$\mathrm{b}_{1}(\nu, \lambda)=\frac{n \pi \nu \mathrm{g}_{1}\left(\lambda^{2}\right)}{1-c_{1}(\nu, \lambda)}$

and

$\mathrm{b}_{2}(\nu, \lambda)=\frac{n \pi \nu \mathrm{g}_{2}\left(\lambda^{2}\right)}{1-c_{2}(\nu, \lambda)}$,

where $\mathrm{g}_{1}(\mathrm{x})={ }_{2} \mathrm{~F}_{2}(1 / 2,1 / 2 ; 1,1 ;-\mathrm{x}), \mathrm{g}_{2}(\mathrm{x})={ }_{2} \mathrm{~F}_{2}$ $(1 / 2,3 / 2 ; 1,1 ;-x)$ and ${ }_{2} F_{2}($.$) is the generalised hyper-$ geometric function :

${ }_{2} \mathrm{~F}_{2}(\mathrm{a}, \mathrm{b} ; \mathrm{c}, \mathrm{d} ; \mathrm{x})$

$=\frac{\Gamma(c) \Gamma(d)}{\Gamma(a) \Gamma(b)} \sum_{m=0}^{\infty} \frac{\Gamma(m+a) \Gamma(m+b)}{\Gamma(m+c) \Gamma(m+d)} \cdot \frac{x^{m}}{m !}$,

with $\Gamma$ denoting the gamma function, and where :

$c_{1}(\nu, \lambda)=\frac{+\mathrm{g}_{1}\left(\mathrm{~d}_{1}^{-1}\right)}{\lambda^{4} \mathrm{~g}_{1}\left(\lambda^{2}\right) \mathrm{d}_{1}^{1 / 2} \mathrm{~d}_{2}{ }^{3 / 2}}$

with $\mathrm{d}_{1}=\left[\lambda^{-2}+1 / 2 n^{2} \pi^{2} \nu \mathrm{g}_{1}\left(\lambda^{2}\right)\right]$

and $\mathrm{d}_{2}=\left[\lambda^{-2}+1 / 2 n^{2} \pi^{2} \nu \mathrm{g}_{2} /\left(\lambda^{2}\right)\right]$,

and $c_{2}(\nu, \lambda)=\frac{\mathrm{g}_{2}\left(\mathrm{~d}_{1}^{-1}\right)}{\lambda^{4} \mathrm{~g}_{2}\left(\lambda^{2}\right) \mathrm{d}_{1}^{3 / 2} \mathrm{~d}_{2}^{1 / 2}}$

The correlation time-scales for axial $(\mathrm{i}=1)$ and transverse $(i=2)$ "random walks" are :

$\tau_{i}=\frac{n T_{0}}{2\left[1-c_{i}(\nu, \lambda)\right]}$

These reduce to Zimmerman's (1976) equations when $n=1$.

\section{Application to the Severn}

In the preceding theory the residual eddies were assumed to be rotationally symmetric. That this is approximately the case for the Severn can be seen from the distribution of eddies shown in Figure 2. An estimate of the average width of eddies for $\mathbf{u}_{T}$ is $5.8 \mathrm{~km}$ (this includes a wide range of sizes from the smallest eddies up to those spanning a whole width), so that $l=2.9 \mathrm{~km}$; with $\left\langle\mathrm{u}^{2}\right\rangle^{1 / 2}=4.6 \mathrm{~cm} \mathrm{sec}{ }^{-1}$ (again averaging over a wide range of values), $\mathrm{U}_{0}=1.2 \mathrm{~m} \mathrm{sec} .^{-1}$ and $l_{0}=$ $8.5 \mathrm{~km}$, then :

$\nu=1.5 \times 10^{-3}$ and $\lambda=2.9$.

The transport residuals, $\mathbf{u}_{r}$, are used to define the eddies rather than $\mathbf{u}$ because they take into account the effects of Stokes drift. As has been pointed out, distributions for $\mathbf{u}_{T}$ and $\mathbf{u}$ are very similar. These values yield $\mathrm{b}_{1}=3.09 \times 10^{-2}$ for $n=8$ (a time-step of $4 \mathrm{~T}_{0}$ ) and $\tau_{1}=8 \mathrm{~T}_{0}$, and $\mathrm{b}_{2}=6.35 \times 10^{-3}$ for $n=6$ (a timestep of $3 \mathrm{~T}_{0}$ ) and $\tau_{2}=6 \mathrm{~T}_{0}$. The transverse and axial dispersion coefficients are, from equation (3) :

$K_{22}=65 \mathrm{~m}^{2}$ sec. $^{-1}$ and $K_{11}=315 \mathrm{~m}^{2} \mathrm{sec}^{-1}$.

This value of $\mathrm{K}_{11}$ is comparable with the yearlyaveraged, spatially-averaged observed value for the region considered $\left(\cong 240 \mathrm{~m}^{2} \mathrm{sec}^{-1}, \mathrm{D}_{3}\right.$ in Uncles, Radford, 1980, p. 716). Values of $K_{11}$ and $K_{22}$ are dependent on the accuracy of $l$ and $\left\langle u^{2}\right\rangle^{1 / 2}$, with $\pm 20 \%$ errors in these variables producing errors of $\pm 24 \%$ and $\pm 20 \%$ respectively in $K_{11}$. The dependence of $K_{11}$ and $K_{22}$ on $l$ and $\left\langle u^{2}\right\rangle^{1 / 2}$ is further demonstrated in the Table, where $l_{0}$ and $U_{0}$ are maintained at $8.5 \mathrm{~km}$ and $1.2 \mathrm{~m} \mathrm{sec}^{-1}$ respectively. Although the assumptions on which the theory is based (homogeneous, normal random distribution of isotropic eddies, each possessing a stream function of Gaussian form) cannot apply exactly to a natural system such as the Severn, it does appear that this mechanism can make a significant contribution to the axial and transverse mixing. An increase in the transverse dispersion coefficient, $\mathrm{K}_{22}$, leads to a decrease in the transverse mixing time. Using $K_{22}=65 \mathrm{~m}^{2} \mathrm{sec}^{-1}$ in equation (2), one obtains a crosssectional mixing time, $\mathrm{T}_{c}$, of 28 days, which is now much less than the flushing time. Further up-estuary the width decreases rapidly, so that the length-scales of the largest eddies must also decrease. This will lead to a decrease in both the transverse and axial dispersion due to the tidal "random walk" mechanism (see later); however, $T_{c}$ depends on the square of the width [equation (2)], so that the reduction in $K_{22}$ is mitigated somewhat by the decrease in width.

Table

$K_{11}$ and $K_{22}$ (in brackets) in units of $m^{2}$ sec..$^{-1}$ for various values of $\left\langle u^{2}\right\rangle^{1 / 2}$ and $l$. The tidal variables $U_{0}$ and $l_{0}$ are taken to be $1.2 \mathrm{~m}$ sec. $^{-1}$ and $8.5 \mathrm{~km}$, respectively.

\begin{tabular}{lllll}
\hline & & & $<u^{2}>^{1 / 2} \mathrm{~cm} \mathrm{sec}^{l-1}$ & \\
\hline 1 & 3 & 5 & $450(70)$ & $490(100)$ \\
$\mathrm{km}$ & 3 & $210(40)$ & $580(220)$ & $810(300)$ \\
& 5 & $350(130)$ & $750(400)$ & $1040(560)$ \\
\hline
\end{tabular}


Finally, it is worthwhile to consider the axial dispersion, $K_{11}$, in more detail. Bowden $(1964$, p. 337) has shown that vertical shear in the tidal currents leads to an axial dispersion coefficient for the Severn of about $5 \mathrm{~m}^{2} \mathrm{sec}^{-1}$. Axial residual currents can also be expected to contribute roughly the same as transverse currents, about $10 \mathrm{~m}^{2} \mathrm{sec}^{-1}$ [from equation (1)]. The axial dispersion due to transverse shear in the tidal currents can be estimated from Fischer et al. $(1979$, p. 235) :

$\mathrm{K}_{11} \cong 0.1<\overline{\mathrm{U}^{2}}>\mathrm{T}_{0} \phi\left(\mathrm{T}_{0} / \mathrm{T}^{\prime}{ }_{c}\right)$,

where here $\langle$.$\rangle is a tidal average, \overline{(.)}$ is a crosssectional average, $U$ is a deviation from the crosssectionally averaged current $U_{0} \sin \omega_{0} t, T^{\prime}{ }_{c}=B^{2} / K_{22}$, and $\phi$ is a function of the ratio of the tidal period to the cross-sectional mixing time-scale, which is plotted by Fischer et al. (1979, Fig. 7.4, p. 235). Assuming a symmetrical cosine distribution of $U$ over each section gives the following form for the instantaneous axial tidal current, $\mathrm{U}^{\prime}$ :

$U^{\prime}=\left[\alpha \cos \frac{2 \pi r}{B}+1\right] U_{0} \sin \omega_{0} t$,

where $r$ is the transverse co-ordinate, with $r=0$ along the axis of the estuary, and $r= \pm B / 2$ at the coasts. The amplitude of the tidal current therefore increases from $(1-\alpha) \mathrm{U}_{0}$ at the coasts to $(1+\alpha) \mathrm{U}_{0}$ along the axis. From Figure 1 a realistic value for $\alpha$ is 0.3 . It follows that :

$\overline{U^{2}}=0.5 \alpha^{2} U_{0}^{2} \sin ^{2} \omega_{0} t$

and $\left\langle\overline{\mathrm{U}^{2}}\right\rangle=0.25 \alpha^{2} \mathrm{U}_{0}^{2}=2.25 \times 10^{-2} \mathrm{U}_{0}^{2}$.

With $\mathrm{K}_{22}=65 \mathrm{~m}^{2} \mathrm{sec}^{-1}$ and $\mathrm{B}=20 \mathrm{~km}$ then $\phi=$ $2 \times 10^{-2}$, and using $\mathrm{U}_{0}=1.2 \mathrm{~m} \mathrm{sec}^{-1}$ gives :

$\mathrm{K}_{11}=3 \mathrm{~m}^{2}$ sec. $^{-1}$.

Lower values of $K_{22}$ lead to even smaller values of $K_{11}$. The combined values of axial dispersion due to vertical shear in tidal and residual currents, together with that due to transverse tidal shear, amount to no more than about $20 \mathrm{~m}^{2} \mathrm{sec}^{-1}$, which is an order of magnitude smaller than the averaged observed values. This emphasizes the importance of the tidal "random walk" mechanism as a contributory factor to the estuary's dispersion properties.

\section{Application to other estuaries}

It is of interest to investigate when tidal "random walk" dispersion is likely to be important for other estuaries. Values of the axial and transverse dispersion coefficients $\left(K_{11}\right.$ and $\left.K_{22}\right)$ have been derived for estuaries of differing widths, $B$, using values of $g_{1}\left(\lambda^{2}\right)$ and $\mathrm{g}_{2}\left(\lambda^{2}\right)$ for large $\lambda$ [see equations (7) and (8)] given in Zimmerman (1976, Fig. $4 a$, p. 427). If it is assumed that these estuaries have the same tidal current speeds as the Severn, and that residual current speeds are of the same magnitude, then $U_{0}=1.2 \mathrm{~m} \mathrm{sec}^{-1}, l_{0}=8.5$ $\mathrm{km}$ and $\nu=1.5 \times 10^{-3}$. The maximum width of horizontal isotropic eddies is limited by the estuary's width; taking the average width of eddies to be $B / 3(\lambda=6$ $l_{0} / \mathrm{B}$ ), as is approximately the case for the Severn), then the following results apply :

$B=5 \mathrm{~km}, \mathrm{~K}_{11} \cong 60 \mathrm{~m}^{2} \mathrm{sec}^{-1}, \mathrm{~K}_{22} \cong 10 \mathrm{~m}^{2} \mathrm{sec}^{-1}$,

$B \doteq 1 \mathrm{~km}, \mathrm{~K}_{11} \cong 10 \mathrm{~m}^{2} \mathrm{sec}^{-1}, \mathrm{~K}_{22} \cong 1 \mathrm{~m}^{2} \mathrm{sec}^{-1}$, and

$B=0.5 \mathrm{~km}, \mathrm{~K}_{11} \cong 3 \mathrm{~m}^{2} \mathrm{sec}^{-1}, \mathrm{~K}_{22} \cong 0.3 \mathrm{~m}^{2} \mathrm{sec}^{-1}$,

Therefore, even with strong tidal and residual flows, this mechanism generally becomes less effective or even insignificant as the estuarine width decreases; that is, for small estuaries or near the heads of large estuaries. Typical values of the axial dispersion coefficient for strongly tidal estuaries are of order $100 \mathrm{~m}^{2} \mathrm{sec}^{-1}$ (Dyer, 1974), so that axial dispersion due to tidal "random walk" appears to be insignificant in estuaries narrower than about $1 \mathrm{~km}$. However, the contribution to transverse dispersion and cross-sectional mixing may still be important in enabling lateral shear-dispersion mechanisms to operate.

Holloway (1981) has attributed the large axial dispersion coefficients in the Bay of Fundy to tidal "random walk", although a quantitative analysis was not undertaken. These coefficients decrease progressing towards the narrow head of the Bay, as would be expected from the preceding results. In contrast, the observed longterm axial dispersion coefficients for the Severn tend to increase as the estuary becomes narrower towards the head (Uncles, Radford, 1980). Because tidal "random walk" generally becomes less effective with decreasing width, other processes must be important in the upper Severn. Comparing the Bay of Fundy with the Severn, then freshwater-induced flows are much higher in the latter, so that shear-dispersion due to residual, buoyancy-driven lateral circulations (Smith, 1980) might be responsible for the up-estuary increase in $K_{11}$. Nevertheless, the parametrization of these lateral shear processes in terms of axial dispersion coefficients requires that the transverse mixing time be appreciably less than the flushing time and, from this first analysis, a suitable mechanism for achieving this appears to be tidal "random walk".

\section{CONCLUSIONS}

A depth-averaged numerical model of the $\mathrm{M}_{2}$ tide has been used to determine residual current patterns due to tidal non-linearities in the Severn Estuary. The dominant generating mechanism for residual flow, and its associated set-up of water level, is advection of $\mathrm{M}_{2}$ tidal momentum. The computed distribution of residual current consists of a number of eddies, and although observations at several stations are in reasonable qualitative agreement with model data, considerably more observations would be necessary to confirm all features of the complicated flow patterns.

The residual currents produce enhanced transverse and axial dispersion by the mechanism of tidal "random walk". Transverse mixing by this process is much larger than that due to other known mechanisms in the wide, seaward stretch of estuary, and, unlike these, 
leads to cross-sectional mixing times which are much less than the flushing time. The axial dispersion coefficient due to residual current eddies is comparable to the observed, long-term value for the seaward section of estuary considered, and is much greater than those values which can be attributed to either vertical shear in tidal and residual currents, or transverse shear in tidal currents.

Axial and transverse dispersion coefficients due to tidal "random walk" decrease with decreasing eddy size for fixed tidal and residual current speeds. Because the maximum size of horizontal isotropic eddies is limited by the estuary's width, it follows that axial dispersion due to this mechanism must become less effective or insignificant as the width decreases. However, the con- tribution to transverse dispersion may still be important in enabling lateral shear-dispersion mechanisms to increase the axial dispersion coefficient.

\section{Acknowledgements}

I am grateful to Miss J.F. Rodgers for assistance with the numerical modelling.

This work, which forms part of the estuarine ecology programme of the Institute for Marine Environmental Research, a component of the Natural Environment Research Council, was partly supported by the Department of the Environment on Contract No. DGR $480 / 48$.
Bowden K.F., 1964. The mixing processes in a tidal estuary, International Conference on water pollution research, London. September 1962, Pergamon Press, 329-346.

Dyer K.R., 1974. The salt balance in stratified estuaries, Estuarine Coastal Mar. Sci., 2, 273-281.

Fischer H.B., List E.J., Koh R.C.Y., Imberger J., Brooks N.H, 1979. Mixing in inland and coastal waters, Academic Press, N.Y., $484 \mathrm{p}$.

Flather R.A., Heaps N.S., 1975. Tidal computations for Morecambe Bay, Geophys. J.R. Astron. Soc., 42, 489-517.

Heaps N.S., 1972. Estimation of density currents in the Liverpool Bay area of the Irish Sea, Geophys. J.R. Astron. Soc., 30, 415-432.

Holloway P.E., 1981. Longitudinal mixing in the upper reaches of the Bay of Fundy, Estuarine Coastal Shelf Sci., 13, 495-515.

Murty T.S., Barber F.G., Taylor J.D., 1980. Role of advective terms in tidally generated residual circulation, Limnol. Oceanogr., 25, 529533.

Nihoul J.C.J., Ronday F.C., 1975. The influence of the tidal stress on the residual circulation, Tellus, 27, 484-489.

Owen A., 1980. The tidal regime of the Bristol Channel : a numerical modelling approach, Geophys. J.R. Astron. Soc., 62, 59-75.

Pingree R.D., 1978. The formation of the Shambles and other banks by tidal stirring of the seas, J. Mar. Biol. Assoc. UK, 58, 211-226.

Pingree R.D., Maddock L., 1977. Tidal residuals in the English Channel, J. Mar. Biol. Assoc. UK, 57, 339-354.

Prandle D., 1978. Residual flows and elevations in the Southern North Sea, Proc. R. Soc. London A., 359, 189-228.

Smith R., 1980. Buoyancy effects upon longitudinal dispersion in wide well-mixed estuaries, Philos. Trans. $R$. Soc. A., 296, 467-496.

Stewart R.W., 1957. A note on the dynamic balance in estuarine circulation, J. Mar. Res., 16, 34-38.
Talbot J.W., Talbot G.A., 1976. Diffusion in shallow seas and in English coastal and estuarine waters, Rapp. P.-V. Réun. Cons. Int. Explor. Mer, 167, 93-110.

Tee K.T., 1976. Tide-induced residual current, a 2-D non-linear numerical model, $J$. Mar. Res., 34, 603-628.

Uncles R.J., 1979. A comparison of the axial distributions of salt and ${ }^{137} \mathrm{Cs}$ in the Severn Estuary during August 1974, Estuarine Coastal Mar. Sci., 9, 585-594.

Uncles R.J., 1981. A numerical simulation of the vertical and horizontal $\mathbf{M}_{2}$ tide in the Bristol Channel and comparisons with observed data, Limnol. Oceanogr., 26, 571-577.

Uncles R.J., 1982. Computed and observed residual currents in the Bristol Channel, Oceanol. Acta, 5, 1, 11-20.

Uncles R.J., Jordan M.B., 1979. Residual fluxes of water and salt at two stations in the Severn Estuary, Estuarine Coastal Mar. Sci., 9, 287-302.

Uncles R.J., Jordan M.B., 1980. A one-dimensional representation of residual currents in the Severn Estuary and associated observations, Estuarine Coastal Mar. Sci., 10, 39-60.

Uncles R.J., Radford P.J., 1980. Seasonal and spring-neap tidal dependence of axial dispersion coefficients in the Severn - a wide, vertically mixed estuary, J. Fluid Mech., 98, 703-726.

Zimmerman J.T.F., 1976. Mixing and flushing of tidal embayments in the Western Dutch Wadden Sea - II, Neth. J. Sea Res., 10, 397-439.

Zimmerman J.T.F., $1978 a$. Topographic generation of residual circulation by oscillatory (tidal) currents, Geophys. Astrophys. Fluid Dyn., 11, 35-47.

Zimmerman J.T.F., 1978 b. Dispersion by tide-induced residual current vortices, in : Hydrodynamics of estuaries and fjords, edited by J.C.J. Nihoul, Elsevier Oceanogr. Ser., Amsterdam, 207-216. 